\title{
Design and Use of a Reactor to Convert Plastic Waste into Useful Fuel
}

\author{
Salim wala. Salah. ${ }^{1}$, Seedahmed A. I. ${ }^{2}$ \\ 1,2: Department of Plastic Engineering, College of Engineering \& Technology of Industries, \\ Sudan University of Science and Technology, Sudan.
}

\begin{abstract}
Conversion of plastic waste into oil fuel is become an important method for the removal of waste from environment as well energy recovery. This study aimed to convert plastic waste materials into useful fuel products. Horizontal and vertical reactors from local materials were designed and used to convert plastic waste such as HDPE and PP into the so called plastic oil, the vertical reactor given better performance than the horizontal for producing oil. $500 \mathrm{ml}$ of the resulting oil was used as fuel to replace the traditional fuel of tuk tuk. Fortunately, tuk tuk traveled distance 1.3 times the distance travelled by same amount of traditional fuel. Plastic oil products were tested for flammability, density and flash point. GCMS, dioxin and furan tests were recommended for future work.
\end{abstract}

Keyword: Plastic Waste, Reactor Design, Waste Into Fuels.

\section{INTRODUCTION:}

Economic growth and changing consumption and production patterns are resulting into rapid increase in generation of waste plastic in the world. The world's annual consumption of plastic material has increased from around 5 million tons in the 1950s to nearly 100 million tons; thus 20 times more plastic is produced today than 50 years ago(UNEP, 2009). This implies that on the one hand, more resources are being used to meet the increased demand of plastic, and on the other hand, more plastic waste is generated.

Due to the increase of generation of waste, plastic waste is becoming the major stream in solid waste. After food waste and paper waste, plastic waste is the major constituent of municipal and industrial waste. Even the cities with low economic growth have started producing more plastic waste due to plastic packaging, plastic shopping bags, PET bottles and other goods/appliances using plastic as the major component. In Sudan the percentage of plastic in waste stream is $12 \%$ (Mohamed, 2010)

Due to lack of integrated solid waste management, most of waste is neither collected properly nor disposed of in appropriate manner to avoid its negative impacts in environment and public health.

Recycling of waste plastic is the one way to decrease the negative impacts by turning it into useful products, thus waste can be converted into resources.

Pyrolsis is one of the methods used for producing liquid fuel from plastic waste (Dalen, 2010). This resource conversion goal is considered to be acceptable as scientific international approach for energy recovery. In Sudan, national governmental as well as private industries will get the benefit of using plastic oil fuel in many areas as a substitute for domestic fuel.

\section{MATERIALS AND METHODS:}

\section{1 materials}

High density polyethylene (HDPE), polypropylene (PP) and mixed plastic was collected and prepared to be used as raw material in the conversion reactor.

\subsection{Equipment}

50 litter Pressure cooker (reactor), copper pipes condenser made from glass, gas stove, electrical heater, rector made from iron, jar, and flask, were used at different stages during the experimental work.

\section{3 methods}

Domestic pressure cooker

50 liter pressure cooker as shown in figure (2.1) was used. The condensation unit was cooper pipes connected to glass condenser.

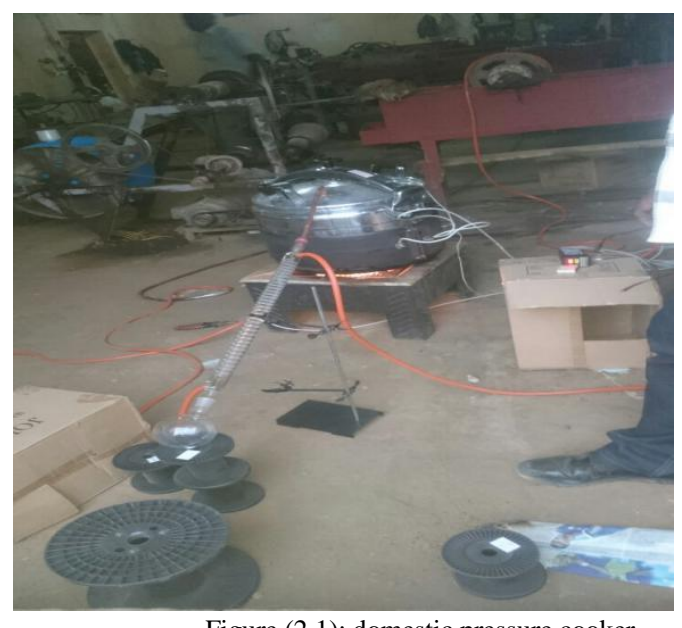

Figure (2.1): domestic pressure cooker

\section{Vertical Reactor VI}

5 liter vertical reactor as shown in figure (2.2) was designed and constructed from iron using local facilities. The condensation unit was a jar of water. 


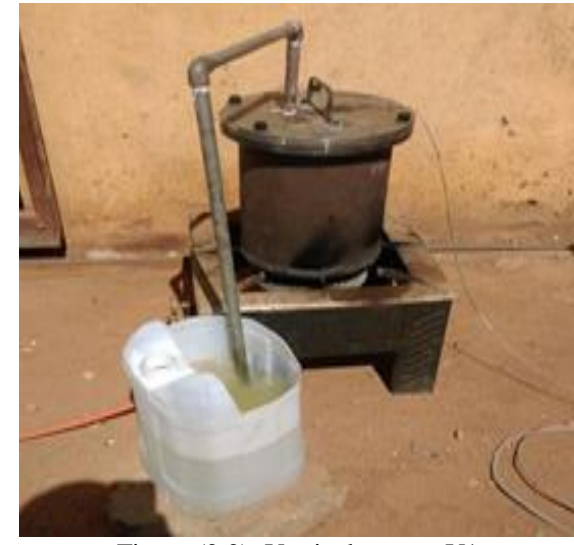

Figure (2.2): Vertical reactor V1

$1 \mathrm{~kg}$ of HDPE plastic waste was placed inside the reactor; reactor closed and heated using a cooker heater for 1 hour. Condensed gas into oil in the surface of the water was collected and its volume was measured. This was repeated for PP Figures (2.2- 2.3)

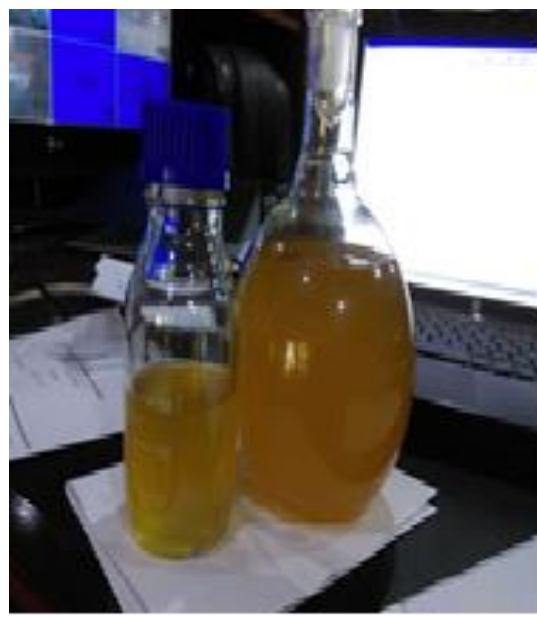

Figure (2.3): Plastic oil from HDPE

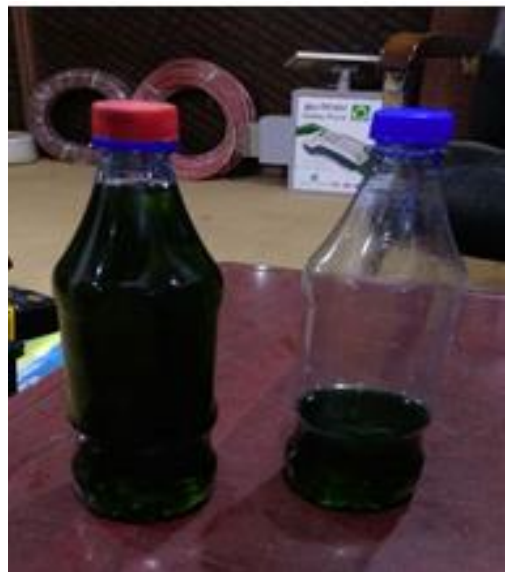

Figure (2.4): Plastic oil from PP

Vertical Reactor $V 2$

In this version the reactor was heated by electrical heater instead of the cooker heater to maintain temperature control in the system. Three electrical heaters were made one in the bottom of reactor and two around it, all of this was connected to electric circuit, Figure (2.5). The operation then was started and after three hours nothing happened except that temperature of heater reached $450^{\circ} \mathrm{c}$ and there is no outcome.

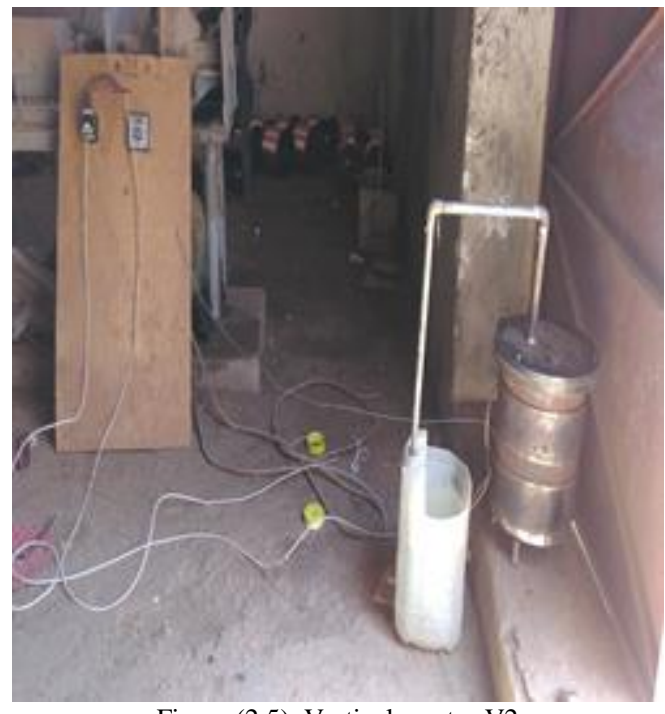

Figure (2.5): Vertical reactor V2

Horizontal Reactor:

In third design trial a horizontal reactor was constructed and conversion system was assembled as shown in figure (2.6). Then same procedure was repeated to produce and collect plastic oil.

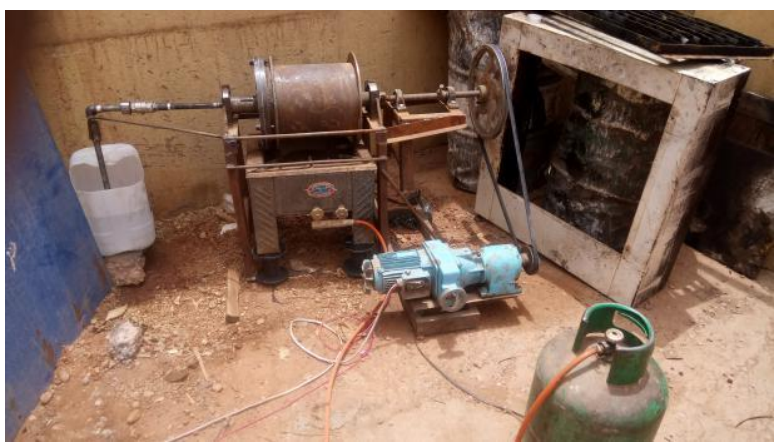

Fig (2.6): Horizontal Reactor

\subsection{Application of Plastic Oil}

$500 \mathrm{ml}$ of plastic fuel and $500 \mathrm{ml}$ of traditional fuel was used separately for Tuk Tuk (traditional 3 legs transport vehicle) and the distances travelled were measured in each case.

\subsection{Testing Plastic Oil}

Plastic oil products were tested for density, flash point, sulfur content and lead content using the following procedures:

- Density was determined according to ASTM D-4052

- Flash point by using open cup theory

- Sulfur content was determined according to ASTM D-4294

- Lead content was determined according to ASTM D- 4691

\section{RESULTS AND DISCUSSIONS \\ Domestic Pressure Cooker}

First trials were done using pressure cooker and electrical heater to heat the plastic. When the test started, pressure watch melted; a 
problem caused probably due to high temperature, besides that, gas released through the hands of cooker and nails. When all these problems were fixed, the cooker becomes not stable and suddenly fired.

\section{Vertical Reactor VI (VRI)}

This type of reactor was very good, the end product is clear and the oil quantity was good. Some problems were arising like some gases escaped in the air and did not condense due to the large surface of the jar.

\section{Vertical reactor $V 2$ (VR2)}

For this trial assumption was deduced that the heating extent was not enough to melt the plastic inside the reactor. So version 2 was rejected.

\section{Horizontal Reactor (HR)}

This trial aimed to encourage the amount of oil produced by rotating the reactor for good temperature distribution. But unfortunately, the result was not good; the final product is wax due to low temperature.

Thus, the vertical reactor V1 was concluded as better design achieved and the rest of the study commenced using VR1

\section{Application of Plastic Oil}

$500 \mathrm{ml}$ of resulting Plastic oil was used in tuk tuk which travelled a distance 1.3 times the distance travelled by same amount of tuk tuk traditional fuel. This insures that the ignition power is better; no problem encountered or noticed during the tuk tuk was running except some smell of oil plastic was not good.

\section{Plastic Oil Properties}

The following results summarize the physical tests conducted to characterize the plastic oil for both HDPE and PP.

Table(2.1): plastic oil properties

\begin{tabular}{|l|c|c|}
\hline \multicolumn{1}{|c|}{ Tests } & $\begin{array}{c}\text { High density poly } \\
\text { ethylene (HDPE) }\end{array}$ & $\begin{array}{c}\text { Poly Propylene } \\
\text { (PP) }\end{array}$ \\
\hline Density g/cm ${ }^{3}$ & 0.78 & 0.76 \\
\hline Flash point ${ }^{\circ} \mathrm{c}$ & 43 & $\begin{array}{c}\text { At room } \\
\text { temperature } \\
\text { which is } 40\end{array}$ \\
\hline Sulfur content $\mathrm{mg} / \mathrm{l}$ & Nil & Nil \\
\hline Lead content $\mathrm{mg} / \mathrm{l}$ & $>0.375$ & $>0.365$ \\
\hline
\end{tabular}

\section{CONCLUSIONS:}

- The vertical reactor is better than the horizontal one.

- Useful products are produced which can be used as fuel for traditional transportation and may be others.

- The results of all tests show encourages future study.

- Plastic oil seems better than the traditional fuel for tuk tuk which give us more kilometers in comparison, which is considered as an important outcome for this work.

\section{RECOMMENDATION}

- More tests like furan, dioxin and distillation test must be done.

- Mixed plastics waste should be used in the future work studies

\section{REFERENCES}

[1] United Nations Environmental Programme, (2009) "converting waste plastic into a resource", compendium of technology, Japan,.

[2] Mohamed, H.S., Mohamed H.K, (2010) "Official Governmental Report"

[3] Dalen M.B, (2010) "Plastic Waste Recycling"

[4] http://www.astm.org $>$ Standards $>$ D4052

3. http://www.astm.org $>$ Standards $>$ D4294

4. http://www.astm.org $>$ Standards $>$ D4691

\section{AUTHOR BIBLOGRAPHY}

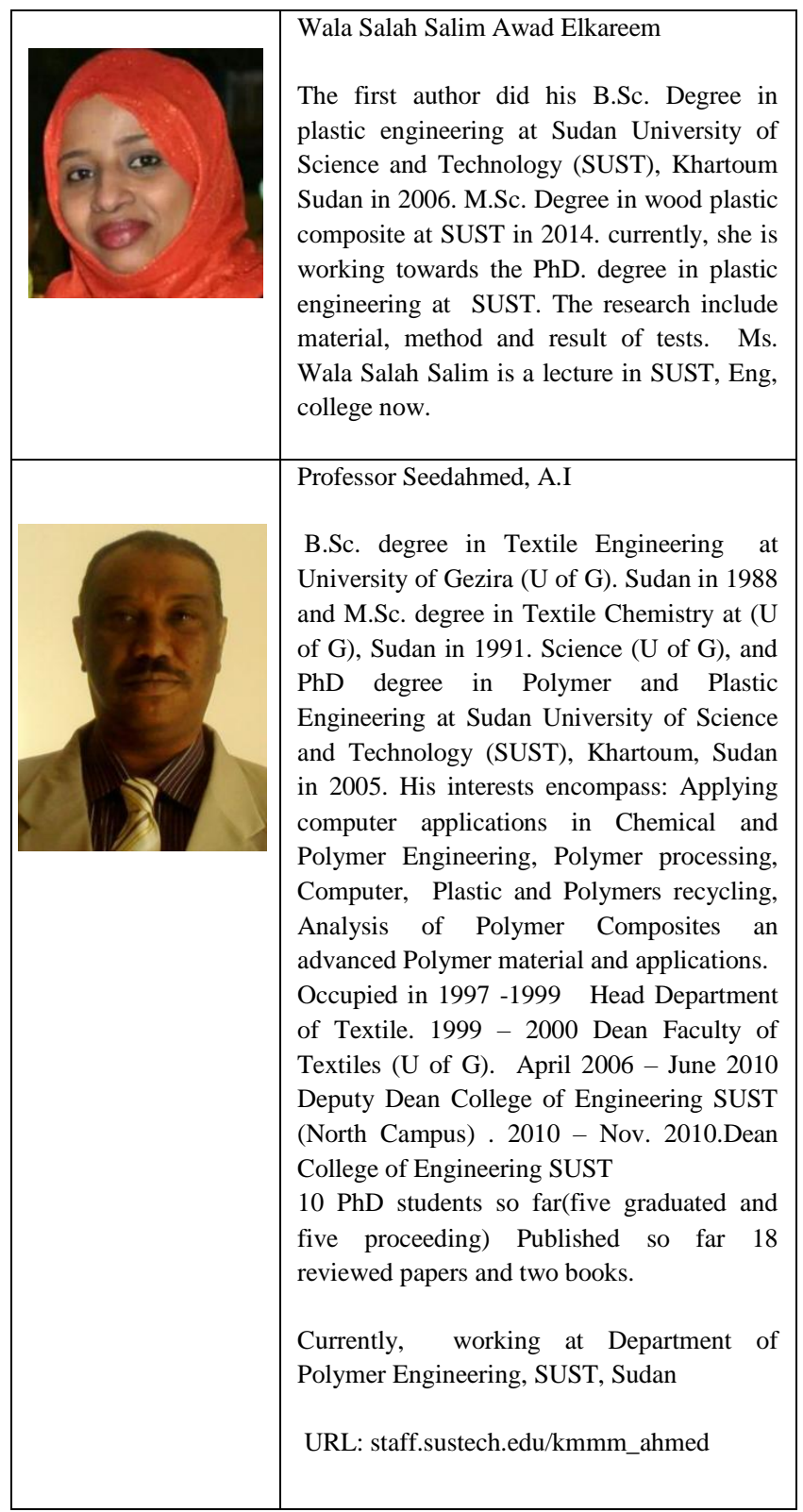

